\title{
EL ALTAR DE JÚIPITER PISTOR (OV. FAST. 6.349-394): UN NUEVO ESPACIO LITERARIO
}

\author{
MARICEL RAdiminsKI \\ Universidad de Buenos Aires - CONICET \\ maricelradiminski@gmail.com
}

La narración de la etiología del altar de Júpiter Pistor (Ov. Fast. 6.349-394) asume el surgimiento de ese sitio cultual como retribución al dios por ayudar a los romanos ante el asedio galo. Roma es presentada como vencida y la construcción de esta derrota se vincula estrechamente con el tratamiento del espacio a lo largo del relato. Asimismo, dicha configuración espacial muestra una singular inclusión de escenarios épicos. Demostraremos que, al alejarse de los elementos y tópicos propios de la epopeya y acercarse al ámbito de la elegía, este relato ovidiano deja ver los mecanismos genéricos del mismo poema.

Ovidio / Fasti / Júpiter Pistor / espacio / templo

\section{THE SHRINE OF JUPITER PISTOR (OV. FAST. 6.349-394): A NEW LITERARY SPACE}

The account of the shrine of Jupiter Pistor (Ov. Fast. 6.349-394) posits that this site was built in acknowledgment of the god's help during the Gallic siege of Rome. Rome is presented as a defeated city and the construction of this defeat is closely linked with the treatment of space throughout the story. Moreover, such spatial arrangement shows a remarkable inclusion of epic stages. We intend to show that, by moving away from elements and topics that are characteristic of the epic genre and towards/into the genre of elegy, the account displays the genre procedures that make up the poem.

Ovid / Fasti / Jupiter Pistor / space / temple 


\section{Introducción: espacios cultuales y espacios literarios}

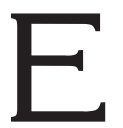

n el libro 6 de sus Fasti ${ }^{1}$ (349-394) Ovidio presenta la etiología del altar capitolino de Júpiter Pistor ${ }^{2}$, dedicado al dios que prestó su favor a los romanos durante el asedio galo. En esa ocasión, Roma se encontraba sitiada y, a raíz de la distribución espacial de la ciudad, quienes estaban allí se hallaban encerrados en su propio territorio, sin posibilidades de luchar ni de huir. La idea de derrota es subrayada por el hambre apremiante, motivo que remite a una condición inaceptable para un pueblo tradicionalmente reconocido como victorioso y conquistador. De hecho, el mismo Marte reclama en el relato un espacio para luchar (locus pugnae, 6.371) que parece negársele a su prole. Si bien la intervención de Júpiter que da lugar al templo rescata a los romanos de esta incómoda situación, la liberación no se produce como resultado de un triunfo bélico, sino que, por el contrario, surge de una estratagema en la que los romanos disimulan la falta de comida arrojándole pan a sus enemigos, treta que también está determinada por la incidencia del espacio en el desarrollo de los acontecimientos. Dicha categoría resulta clave en la configuración del episodio ovidiano por sus alcances doblemente socio-culturales y literarios. En efecto, según la caracterización de De Certeau ${ }^{3}$, el espacio es un "lugar" practicado", es decir, un sitio atravesado por "el efecto producido por las operaciones que lo orientan, lo circunstancian, lo temporalizan y lo llevan a funcionar como una unidad polivalente de programas conflictuales o de

1 El texto latino corresponde a la edición de Alton-Wormell-Courtney (1985).

2 De un modo general, este episodio de Fasti no ha despertado demasiado interés en los estudiosos de la literatura latina. En cuanto a las ediciones comentadas del poema, FRAzER (1929 [1989]: 344-346) consagra apenas dos notas al altar de Júpiter Pistor. Si bien el erudito comentario de BÖMER (1958:363-365) brinda algo más de información, ScHILLING (1993: 180-182) y CANALI (2016 [1998]: 470-475) lo tratan también de manera acotada. Solo la edición de LiTTLEWOOD (2006: 112-123) del sexto libro de Fasti ofrece un comentario minucioso del pasaje. Por su parte, los estudios críticos tampoco se han detenido en él: el consagrado trabajo de HEINZE (1919: 68-69) se ocupa brevemente de esta etiología, al igual que FANTHAM en su revisión del encuentro fallido entre Príapo y Vesta (1983: 206 207) y en su recapitulación de los nuevos abordajes de Fasti (1995: 57). Lo mismo hace MALEUVRE (1997: 74-75) al revisar la figura de Júpiter, y BARCHIESI (1997: 20) lo menciona someramente. Newlands (1995: 124-145) se detiene algo más en el cuarto capítulo de su libro, donde lo trata junto a otros pasajes relativos a la figura de Vesta, mientras que WiLLIAMS (1991: 185-188) estudia el episodio desde el punto de vista narrativo en el marco de su estudio sobre los Vestalia. Para una completa revisión del estatus literario de este relato, cf. MERLI (2000: 153-199).

3 Cf. De Certeau (2007:129).

4 El autor distingue el concepto de 'espacio' del de 'lugar', que define como "el orden (cualquiera que sea) según el cual los elementos se distribuyen en relaciones de coexistencia" (De CerTEAu, 2007:129). 
proximidades contractuales". En este sentido, el espacio se constituye como tal a partir de las experiencias de las que los distintos actores sociales lo hacen participar y engloba tanto a grandes espacios urbanos como a los pequeños espacios que forman parte de él. La representación de esos ámbitos en la literatura implica, a su vez, su integración a un continuum espacio-temporal narrativo en pos de la construcción de un universo ficcional coherente ${ }^{5}$.

El levantamiento de un nuevo altar o templo constituye, naturalmente, una edificación fija, visible y palpable, que no solo se integra a la geografía citadina, sino que evoca necesariamente las circunstancias que han inspirado su inclusión en ese determinado lugar ${ }^{6}$, es decir, la conmemoración de diversos episodios relevantes para la sociedad en la que se inscribe. Así pues, la instauración y permanencia de monumentos en escenarios cotidianos se vincula directamente con diversos factores ideológicos que se plasman en el espacio (y en el tiempo) y, a medida que lo modifican, participan en la construcción y consolidación de la identidad de la comunidad. En lo que hace a la inclusión de los antiguos templos en la literatura romana y a sus alcances como asunto literario, se trata sin duda de una temática cuya solemnidad supone un formato acorde como el verso épico en tanto soporte de un género tradicionalmente reconocido como adecuado para el tratamiento de temáticas de esta índole. Lo mismo cabe para los enfrentamientos bélicos que suelen dar lugar a estas edificaciones, dado que suelen transmitirse también por medio de la epopeya. El episodio del libro 6 de Fasti conjuga ambos elementos al presentar el surgimiento de un espacio cultual a partir de una instancia de sometimiento que resulta de la imposibilidad de encontrar un espacio de lucha. No obstante, Ovidio los inscribe paradójicamente en el marco elegíaco que da forma a su calendario, asunto que también parece ser más apropiado para el hexámetro que para el dístico, comúnmente asociado a temáticas menores. La declaración programática de 1.13-14 muestra el presunto rechazo por la materia bélica (arma canant alii, 1.113) y la elección de arae y dies (1.13-14) como asunto preponderante del texto, exhibiendo así, desde su comienzo, un estatus genérico difícil de determinar. Por sus mismas características y por las ambigüedades que se desprenden de su configuración textual, la etiología del altar de Júpiter Pistor nos resulta particularmente significativa dentro del proyecto estético ovidiano. Desde una perspectiva poético-ge-

5 Cf. SKempIS - ZIOGAS (2014: 2).

6 La inclusión de nuevos templos en Roma suele responder a la intención de homenajear a distintas divinidades —ya sean locales o foráneas (cf. OrLIN, 1997: 11) — cuyas intervenciones resultan significativas para la historia de la ciudad (cf. STAMBAugh, 1978: 551). Dichas construcciones visibilizan así determinados aspectos de la cultura, la política y la religión romanas.

Argos 40 (2017) ISSN 0325-4194, pp. 84-104 
nérica, analizaremos el funcionamiento de los espacios en ese relato con vistas a mostrar que la etiología del templo remite emblemáticamente a la hibridez ${ }^{7}$ misma de Fasti al distanciarse del motivo épico tradicional y acercarse al ámbito elegíaco en una dinámica de entrecruzamientos y resignificaciones en diversos niveles del episodio. Así pues, distribuiremos el desarrollo de nuestro trabajo en cuatro secciones: la primera, "El templo: Júpiter Pistor y un culto al pan", donde nos detendremos en el templo propiamente dicho, el epíteto del dios y el vínculo que establece el texto entre la historia de esta etiología y la fabricación del pan; la segunda, "El sitio: la batalla de Alia y el quiebre de expectativas del motivo épico", en la que recuperaremos la temática del asedio galo, su plasmación en Fasti y la consecuente configuración de Roma como una ciudad presta a ser vencida; una tercera, "La ausencia del espacio de batalla y la configuración de una Roma derrotada", dedicada a la configuración del espacio en la Roma sitiada y al tratamiento de los distintos motivos épicos que allí pueden verse; y una cuarta, "La etiología de un nuevo espacio literario", consagrada a la liberación de los romanos por intermedio del pan y el posterior levantamiento del templo de Júpiter Pistor. Finalmente, incluiremos un último apartado con nuestras conclusiones.

\section{El templo: Júpiter Pistor y un culto al pan}

El altar de Júpiter Pistor constituye una ambigüedad en sí mismo: la edificación se menciona únicamente en este pasaje de Fasti y en Institutiones divinae de Lactancio (1.20.33), quien probablemente haya utilizado a Ovidio como fuente. De hecho, Tito Livio (5.48.4-9), Floro (Epit. 1.7.1517) y Valerio Máximo (7.4.3) toman la saga de los galos y el motivo del hambre pero en ningún momento mencionan este templo ${ }^{8}$. Tampoco se hace referencia a él en la descripción virgiliana del escudo de Eneas ( $A$. 8.652-662), con lo cual, al no haber claros testimonios de este culto ni de la existencia del altar, todo dato se reduce a una mera conjetura. Williams ${ }^{9}$ desacredita incluso la posibilidad de que esta historia haya dado lugar a la construcción del templo, dado que la versión de Ovidio 'desentona' con la omisión por parte de otros autores. El mismo epíteto Pistor ("panadero") resulta por demás llamativo puesto que apela a una faceta del dios que no

7 Dada la mixtura genérica presente en este texto, nos referimos a Fasti como 'híbrido' tomando la definición que Dalzell (1996: 139) emplea para el Ars Amatoria.

8 En Val. Max. (7.4.3) el episodio del pan se presenta como una estratagema que resalta la agudeza y el ingenio de los romanos y permite su salvación, mas nada se dice del supuesto templo del dios. Si bien se menciona la intervención de Júpiter para que la empresa romana concluya positivamente, en ningún momento se lo llama pistor.

9 Williams (1991: 185). 
es posible corroborar en las fuentes que se conservan. Tampoco hay certezas en cuanto al significado concreto del término: Porte ${ }^{10}$ considera distintas posibilidades y resalta el hecho de que Pistor podría derivar del verbo pinsere $^{11}$ ("golpear", "machacar", "moler"), acepción propicia para aludir a la molienda de granos u otros materiales; Williams ${ }^{12}$, por su parte, observa que la relación etimológica entre Pistor y pinsere habilita a Ovidio a caracterizar al dios como "crusher", ya sea de granos o de enemigos, cuestión que puede constatarse en el texto dado que, como Júpiter ayuda a los romanos a repeler a su adversario arrojándole pan, el dios queda asociado a ambos elementos. Este último punto de vista se torna aún más interesante a partir de las palabras de Littlewood ${ }^{13}$, quien al afirmar que "the sense of pounding in the word pinsere makes it possible that the title luppiter Pistor might also be connected to Iuppiter Tonans, the Thunderer, whose temple stood nearby on the Capitolium", permite considerar la posibilidad de que el templo de Júpiter Pistor se esté confundiendo aquí con este último, dedicado en el 22 a.C. En virtud de dicha ambivalencia, coincidimos con Williams ${ }^{14}$, para quien "uncertainty over Jupiter's title conveniently exemplifies the poet's manipulation of ambivalent elements in his narrative", y creemos pertinente asumir esa ambigüedad como tal y otorgarle un sentido en relación con la naturaleza misma del texto ovidiano.

A este respecto, cabe mencionar que el episodio en cuestión forma parte de la fiesta de los panaderos, celebración que tenía lugar durante los Vestalia (Fast. 6.249-460) y contaba con las Vestales para la preparación de la mola salsa ${ }^{15}$, de modo que la etiología del altar se asocia estrechamente con la diosa Vesta en el texto de Ovidio. Más aún, esa relación explica la presencia del fuego que, además de ser un elemento característico de Vesta, formaba parte del proceso de cocción del pan, según señala el ego enunciador de Fasti al delimitar esta festividad:

\author{
Ecce coronatis panis dependet asellis, \\ et velant scabras florida serta molas. \\ sola prius furnis torrebant farra coloni \\ (et Fornacali sunt sua sacra deae): \\ subpositum cineri ${ }^{P}$ panem ${ }^{H}$ focus ipse parabat,
}

10 Para un repaso de la historia del término, cf. PORTE (1985: 365-368). Cf. también WiLLIAmS (1991: 185-187), NeWLands (1995: 133-134, n. 34) y Merli (2000: 155, n. 2 y 3).

11 OLD s.v. pi(n)so

12 Cf. WilLiams (1991: 186).

13 Según LiTTLEWOOd (2006: 113-114), esto resulta evidente en la mención a luppiter Tonans en Fast. 6.349-350.

14 Cf. Williams (1991: 187).

15 Se trata de una mezcla de harina y salmuera que se utilizaba en determinados rituales y se ofrecía en el altar de la diosa Vesta (cf. LitTLEWood, 2006: 114). 
strataque erat tepido tegula quassa solo.

inde focum servat pistor dominamque focorum

et quae pumiceas versat asella molas. (Fast. 6.311-318).

He aquí que la hogaza de pan cuelga de los asnillos adornados con coronas y las floridas guirnaldas cubren las rugosas piedras del molino. Anteriormente, los granjeros solo cocían espelta en los hornos (y la diosa de los Hornos tenía sus ritos): el mismo fuego del hogar preparaba el pan puesto bajo la ceniza y en el suelo caliente se echaba una teja rota. Desde entonces el panadero rinde culto al hogar y a la dueña del hogar y a la asnilla que hace girar las ásperas piedras de pómez.

Además de la mención del pan y el fuego, resulta aquí fundamental la participación del burro o asnillo en el proceso de molienda del trigo ( $\mathrm{mo}$ las, $312 ; 318$ ) pues, en la medida en que el animal colabora con el empleo de la maquinaria, parece aludir metafóricamente a prácticas propias del quehacer literario. En efecto, las pumiceas molas (318) para las que el asno es utilizado remiten al procedimiento de fabricación del panificado y, al mismo tiempo, al pulido de la escritura en la tradición literaria a través del uso del adjetivo pumiceas ${ }^{16}$. Desde una misma perspectiva metapoética, la mención de los coronatis asellis (311) refiere programáticamente al discurso elegíaco de Propercio (Vesta coronatis pauper gaudebat asellis, [Vesta, en su pobreza, disfrutaba de los coronados asnillos] 4.1.21) ${ }^{17}$, lo cual subraya la relación del episodio de Fasti con la elegía etiológica de anclaje calimaqueo y contribuye a delinear aún más el marco literario en el que se inscribe este episodio. La estructura en anillo del pasaje, que se abre y se cierra con la imagen del asno (asellis, 311; asella, 318), insiste, a su vez, en la relación entre Vesta y dicho animal. Por un lado, la centralidad del término panem ubicado entre las cesuras $\mathrm{P}$ y $\mathrm{H}^{18}$ del verso 315 y seguido por el sustantivo focus destaca la correspondencia entre la llama de Vesta y el pan, efecto que condensa el verso 317 al completar la imagen ígnea con el poliptoton focum - focorum e incluir tanto la figura del panadero (pistor) como la de la diosa, que es llamada domina, en un claro gesto alusivo al léxico propio de la elegía de asunto erótico ${ }^{19}$. Este entra-

16 Cf. Cat. 1.2: Cui dono lepidum novum libellum / arida modo pumice expolitum? [¿a quién regalo mi novedoso y agradable librito, pulido cuidadosamente con la árida piedra pómez?].

17 LitTLEWOOd (2006: 99-100) advierte esta relación intertextual y la vincula con la antigua tradición de adornar a los asnillos con coronas y guirnaldas durante los Vestalia.

18 Designamos con los signos $(\mathrm{P}),(\mathrm{T})$ y $(\mathrm{H})$ a las cesuras pentemímeras, triemímeras y heptemímeras del hexámetro respectivamente, siempre que la métrica resulte relevante para nuestro análisis.

19 Cf. Pichon (1991). 
mado léxico-semántico adquiere relevancia en la dinámica general de los Vestalia, puesto que da pie al poeta para continuar luego con la historia de Príapo y Vesta (6.319-348 ${ }^{20}$ ), donde el rebuzne de un asno despierta a la diosa dormida e impide que sea violada por el dios, a raíz de lo cual Vesta adorna el cuello de su "protector" con un collar de pan. El cierre de dicho encuentro sexual frustrado asocia doblemente el final de esta aventura con la ornamentación del asno y con la culminación de la fabricación del pan: quem tu, diva, memor de pane monilibus ornas; / cessat opus, vacuae conticuere molae, 6.347-348 [Tú, diosa, adornas (al asno) con collares de pan como recuerdo. Termina la obra; callaron las muelas vacías]. Al ser designado como opus, el proceso de panificación activa los alcances metaliterarios de dicho término en el poema pues permite entenderlo como 'obra literaria'. La descripción de la fabricación del pan parece aludir, así, a la 'fabricación' del texto, cuestión que resulta significativa puesto que dadas las distintas referencias intertextuales y la inclusión de Vesta en un episodio amoroso, parece promover una temática ceremonial como los Vestalia a través de un encuadre elegíaco. Esta ambigüedad genérica está presente a lo largo del relato etiológico que nos ocupa y da cuenta de la manipulación poética que opera en el calendario ovidiano y, tal como veremos a continuación, el tratamiento de la batalla de Alia no es la excepción.

\section{El sitio: la batalla de Alia y el quiebre de expectativas del motivo épico}

El episodio que nos ocupa se relaciona con la batalla de Alia y el posterior saqueo de la ciudad, ocurridos presuntamente en el 390 a.C. ${ }^{21}$, hechos que incluyen una serie de enfrentamientos entre Roma y la Galia. Según Tito Livio (5.38-49), ambos ejércitos se enfrentaron a orillas del río Alia, donde se vio derrotada la facción romana al intentar huir de los galos. Algunos quirites murieron in situ, otros escaparon a Veyes y un tercer grupo retornó a Roma sin siquiera cerrar las puertas de la ciudad. Al llegar los galos y ver que no había impedimentos para ingresar, asumieron esto como una posible trampa y decidieron demorar su entrada a la ciudad hasta el día siguiente. Los romanos, ignorando que gran parte del ejército estaba en Veyes, consideraron que los únicos sobrevivientes eran los soldados que habían retornado a Roma, con lo cual determinaron que los hombres en edad militar se refugiarían, junto a sus esposas e hijos, en la ciudadela y en el Capitolio. El alimento escaseaba y el hambre comenzaba a asediar

20 En Fast.1.399-440 la historia de Sileno y Lótida se desarrolla en circunstancias similares. Para el tratamiento de los vínculos entre ambos episodios, cf. FANTHAM (1983: 201-209), NeWLANDS (1995: 124-145).

21 También se estima que pudo haber ocurrido en el 387 o 386 a.C. (cf. Horsfall, 1981: 298). Ogilvie (1965: 717-718) fecha el evento un 18 de julio. 
a ambos ejércitos (los galos, inclusive, se vieron afectados por una peste a causa del clima de Roma y del contacto con los cadáveres que el asedio dejaba como saldo), pero los romanos lograron disimularlo arrojándole pan al enemigo. Esto condujo finalmente a la necesidad de negociar una especie de tregua entre uno y otro ejército, que consistió en la compra de la libertad romana en mil libras de oro. Sin embargo, este acuerdo quedó sin efecto tras la vuelta de Furio Camilo a Roma, quien, después de haber sido designado dictator, volvió a su patria y la instó a sobreponerse por medio de las armas y no del dinero, lo cual derivó en la victoria romana.

La versión de Ovidio difiere sustancialmente de la de Livio en distintos aspectos. Si bien la narración historiográfica no muestra a los guerreros romanos en actitudes plenamente heroicas puesto que en ocasiones los presenta huidizos en la batalla y prestos a comprar su libertad mediante el ofrecimiento de dinero a los galos (Liv. 5.48), la aparición de Camilo y la recuperación de la honra romana por medio de las armas (Liv. 5.49) parecerían matizar esos aspectos. Por su parte, el ego poético de Fasti se concentra especialmente en el asedio romano y lo plantea como una situación de absoluta vulnerabilidad, donde el ejército local se encuentra relegado en el Capitolio, sin posibilidades de luchar. Esta circunstancia llega a su extremo a causa de la hambruna que sufren los romanos durante el sitio de la ciudad, que se añade al hecho de que los galos especulaban con poder aprovecharse de esa situación para vencer definitivamente. Ovidio no incluye cuestiones como la desconfianza de los galos ante la ciudad desprotegida ni el hambre que, sumado a la peste que los amenazaba (Liv. 5.38), pone a este ejército en una situación de debilidad no tan distinta de la romana. Igualmente curioso resulta que no se haga mención alguna del primer ataque galo, frustrado por unos gansos que despiertan a Man$\operatorname{lio}^{22} \mathrm{y}$, al permitirle advertir a sus compañeros y repeler esta agresión con lanzas y piedras, promueven la momentánea salvaguarda de Roma ${ }^{23}$ (Liv. 5.47.1-5). También se omite en el poema ovidiano la opción del abandono del asedio a cambio de mil libras de oro (Liv. 5.48), quizás para eludir, así, la intervención final de Camilo ${ }^{24}$ (Liv. 5.49). Queda claro, entonces, que la selección ovidiana a la hora de tratar el asunto de Alia apunta fundamentalmente a la configuración de un escenario sombrío y desesperanzado

22 Para el motivo de Manlio y los gansos, cf. Horsfall (1981).

23 Podríamos pensar que esta advertencia por parte de un animal se da de modo similar a la del asno que, como notamos anteriormente, resguarda la virginidad de la diosa Vesta en Fasti.

24 Manlio y Camilo son mencionados en Fast. 6.183-190 a propósito de la edificación del templo de Juno Moneta. Se recuerda la acción de Manlio ante el asedio galo (Fast. 6.185186) pero en 6.189 se hace hincapié en sus supuestas aspiraciones a convertirse en rey, cuestión que le vale su ejecución en el año 384 a.C. Para el tratamiento que Ovidio hace de ambas figuras en este breve pasaje, cf. PAsco-Pranger (2006: 259-275). 
ante la inminencia de la derrota. Fasti elude los elementos anteriormente mencionados para centrarse, más bien, en el detalle del disimulo de la falta de alimento a través del lanzamiento del pan, lo cual expone una vez más la imposibilidad de los romanos para sortear el asedio por medio de su propia destreza militar. El ego poético orienta hacia esta lectura en el comienzo mismo del relato: Nomine quam pretio celebratior arce Tonantis / dicam Pistoris quid velit ara Iovis, 6.349-350 [Diré qué significado tiene el altar de Júpíter Pistor, más famoso por su nombre que por su valor y ubicado en el alcázar del Tonante]. El nombre del templo, que conmemora a Júpiter (Tonantis, 349; lovis, 350) y al pan (Pistoris, 350), parece haberse extendido más que la importancia del sitio mismo (nomine quam pretio, 349). Esto resulta relevante en términos literarios pues, dado que el propósito inicial de los Fasti no son los arma sino las arae (1.13), la historia que nos ocupa introduce un elemento disruptivo al implicar el levantamiento de un templo en el marco de un escenario de batalla. El código épico se ve problematizado al mostrar una Roma víctima de sus propias imposibilidades y salvada por el pan. Tal disrupción se torna evidente en la configuración espacial de la ciudad sitiada, presentada como un espacio derrotado que, al encerrar a sus propios hombres en esa derrota, los deja a un paso de la muerte, temerosos y sin grandes posibilidades de acción.

\section{La ausencia del espacio de batalla y la configuración de una Roma derrotada}

La exitosa performance de los romanos en la lucha armada constituye un leitmotiv de la tradición literaria de la Urbs. Si, como recuerdan Skempis y Ziogas ${ }^{25}$, esta aptitud dominante en la guerra se traslada a los modos de manipulación del espacio épico romano, el episodio que nos ocupa se presenta de un modo peculiar:

cincta premebantur ${ }^{\mathrm{P}}$ trucibus Capitolia Gallis:

fecerat obsidio iam diuturna famem.

$(6.351-352)$

Rodeado por los salvajes galos, el Capitolio estaba sitiado y el asedio prolongado ya había suscitado el hambre.

La situación de asedio (cincta...Capitolia; premebantur; obsidio) descalifica a los romanos como guerreros y los convierte en prisioneros dentro de su propio espacio. La brevedad de la imagen, condensada en un solo dístico, adquiere gran espesor semántico a partir de su trabajada construcción textual: por un lado, la distribución de las palabras del hexámetro des-

25 Cf. SKEMPIS - ZIOGAS (2014: 5). 
taca la imagen del sitio a partir de la ubicación focalizada del participio en el comienzo (cincta) y del sentido del verbo que le sigue (premebantur), cuya extensión en el resto del primer hemistiquio alude, en la materialidad o 'espacialidad' del verso, a la extensa duración de las circunstancias; por otro, el segundo hemistiquio refuerza tal imagen a partir de la disposición del Capitolio en el centro del sintagma disociado (trucibus...Gallis). Más aún, dado que las tres primeras palabras del verso insisten progresivamente en el estado de sitio propiamente dicho (cincta), en la acción que lo designa (premebantur) y en la cualidad distintiva de los agentes del saqueo (trucibus), el ojo del lector llega a la palabra Capitolia teñido de imágenes que marcan la sumisión del espacio romano por parte de los galos. Por añadidura, el estatuto simbólico del Capitolio habilitaba la interpretación de la invasión gala como la violación de un espacio sagrado, y la impotencia de los romanos al refugiarse allí destaca cierta ineficiencia a la hora de impedir su profanación. La callida iunctura "Capitolia Gallis" hace hincapié en el sometimiento, cuya consecuencia directa es, como muestra el pentámetro, la instalación del hambre (famem). La duración de ese estado y la imagen de un debilitamiento de los romanos cautivos son nuevamente subrayadas por la yuxtaposición de este término con el adjetivo diuturna. Si a esto se le suma el hecho de que el Capitolio era una colina elevada y que, una vez en la cima, la única opción para abandonar dicho recinto era el descenso, los romanos se encontraban presos no solo del asedio galo sino también de su propia geografía ${ }^{26}$. Todo esto marca una clara desigualdad entre el ejército local y el invasor, lo cual, como señala Newlands ${ }^{27}$, no se condice con el clásico escenario épico: "The traditional site for violence in epic is the battlefield, and that site is characterized by face-to-face combat among men who are in general equally matched".

Ante esa situación sin salida, Júpiter convoca una asamblea de dioses y el relato incluye, así, el motivo épico del concilium deorum ${ }^{28}$. Esta

26 En Fast. 2.193-242 se narra la batalla de Crémera, librada entre Roma (representada por los Fabios) y Veyes en el siglo V a.C. En este episodio la descripción del espacio de batalla es también elocuente en términos literarios, pues los Fabios son vencidos a partir del encierro que genera la misma geografía del espacio de batalla. A su vez, dicho espacio es sumamente particular dado que el río es descripto como rapax y turbidus (2.205-206, 2.219-220) y su curso precipitado que arrastra las aguas residuales del invierno evoca el río Asirio de Calímaco (Ap. 105-130), que funciona como metáfora del género épico por contraposición a la levitas que caracteriza a la elegía. El único sobreviviente de esta gens es un joven que no acude a la batalla pues su corta edad no le permitía empuñar las armas (2.239-241). Para el estudio de este pasaje, cf. RichARD (1990); HARRIES (1991); MERLI (2000: 201-264); RoBinson (2011: 178-197).

27 Newlands (2005: 481).

28 Merli (2000:158) y Littlewood (2006:114) explicitan los alcances épicos del motivo del concilium deorum. Cabe señalar que el mismo Ovidio despliega este tópico en Met. 
reunión ${ }^{29}$ se desarrolla, naturalmente, en el Olimpo, es decir, en otro de los espacios característicos de la épica, destinado al exclusivo alojamiento de los dioses y, por lo tanto, marcador del límite entre el mundo humano $\mathrm{y}$ el divino y de las diversas interacciones entre uno y otro ${ }^{30}$. Como bien observa Merli ${ }^{31}$, la asamblea se construye como una "parodia di un concilium deorum", dado que altera muchos de los elementos propios de esas escenas. De hecho, el texto no describe el espacio donde tiene lugar la asamblea; la reunión se abre súbitamente con la palabra de Marte (quien aboga a favor de los romanos y pide a Júpiter por la reivindicación de la patria de Rómulo) y no hay discursos argumentativos por parte de otras divinidades, de quienes solo se menciona apenas su postura (tunc Venus et lituo pulcher trabeaque Quirinus / Vestaque pro Latio multa locuta suo est, [Entonces Venus, el bello Quirino con su trompeta y su trábea y Vesta dijeron muchas cosas a favor de su Lacio], 6.375-376). En esta línea paródica entendemos que se inscribe el discurso de Marte (6.355-374) ${ }^{32}$, que ocupa la mayor parte del concilium. El parlamento del dios, que vuelve sobre la descripción del espacio romano sitiado, toma distintos elementos épicos para resignificarlos e instaurar ciertos desvíos respecto del mismo:

'scilicet ignotum est quae sit fortuna malorum,

et dolor hic animi voce querentis eget.

si tamen ut referam breviter mala iuncta pudori

exigis, Alpino Roma sub hoste iacet.

haec est cui fuerat promissa potentia rerum,

Iuppiter? hanc terris impositurus eras?

360

iamque suburbanos Etruscaque contudit arma:

spes erat in cursu: II nunc lare pulsa suo est.

vidimus ornatos aerata per atria picta

veste triumphales occubuisse senes;

vidimus Iliacae transferri pignora Vestae

1.163-252. Para el estudio de este pasaje en relación con el espacio y el poder, cf. ScHNIEBS (2016).

29 LitTLEWOod (2006:114-115) muestra que la disposición de esta asamblea es similar a las reuniones en el Senado, pues los dioses son convocados (superis vocatis, 353); Júpiter ordena a Marte abrir el debate (incipe, 354); el dios se limita a lo estrictamente necesario (referam breviter, 357); dicen muchas cosas (multa locuta est, 376) y finalmente Júpiter propone una moción (publica cura est, 377) que resulta aprobada (adnuit, 384).

30 SKEMPIS - ZIOGAS (2014: 6-7).

31 Cf. MerLI (2000:161).

32 MerL (2000:162-175) analiza detalladamente el discurso de Marte y lo vincula con distintos parlamentos épicos. 
sede: putant aliquos scilicet esse deos.

at si respicerent qua vos habitatis in arce

totque domos vestras obsidione premi,

nil opis in cura scirent superesse deorum,

et data sollicita tura perire manu.

atque utinam pugnae pateat locus; arma capessant,

et, si non poterunt exsuperare, cadant.

nunc inopes victus ignavaque fata timentes

monte suo clausos barbara turba premit.' (Fast. 6.355-374)

Evidentemente, vosotros ignoráis la fortuna de nuestros males y este dolor no tiene la palabra de un espíritu quejoso. Sin embargo, si me pides que cuente brevemente los males unidos a la vergüenza, Roma yace postrada a los pies del enemigo alpino. ¿Esta es la ciudad a la que le prometiste el poderío de todo el mundo, Júpiter? ¿A esta ibas a poner al mando de la tierra? Ya había aplastado a las ciudades cercanas y las armas etruscas, la esperanza seguía su curso; ahora ha sido expulsada de su propia casa. Vimos ancianos triunfantes, ornamentados con vestimenta bordada, morir en los vestíbulos decorados con bronce; vimos que las prendas de la Vesta de Ilión eran trasladadas de lugar: evidentemente, [los romanos] piensan que hay algunos dioses. Pero, si se volviesen a mirar en la fortaleza que vosotros habitáis, y viesen tantas casas vuestras sitiadas por el asedio, sabrían que ninguna ayuda hay en la observancia de los dioses y que el incienso brindado con mano diligente era en vano. ¡Y ojalá se abra un lugar para luchar! Que tomen las armas y, si no pueden vencer, que sucumban. Ahora, faltos de comida y temiendo una muerte cobarde, encerrados en su propia colina, los asedia una turba bárbara.

Como señala Merli ${ }^{33}$, el comienzo del discurso de Gradivo (scilicet, 6.355) remite tanto a la reacción de Eneas al ver a Helena en Verg. A. 2.577 como a la de Juno ante la maternidad de Calisto en Ov. Met. 2.471. En el marco de esa doble relación de las palabras del dios con un parlamento épico propiamente dicho como la epopeya virgiliana y con otro de carácter híbrido como los hexámetros ovidianos ${ }^{34}$, coincidimos con la autora en que ambos manifiestan cierta indignatio por parte del personaje que, con propósitos persuasivos, apunta a convencer a los dioses para modificar la situación de los romanos. Los dichos de Marte amplían así los alcances del relato de Fasti al hacer confluir en él elementos provenientes de dos

33 Cf. Merli (2000:163).

34 Para el debate acerca del género literario de las Metamorphoses ovidianas, cf. NewLANDS (2005: 477-481). 
poemas de distinta filiación genérica y articularlos a través de un discurso cuya marcada configuración retórica subraya dicha ampliación.

Los primeros dos dísticos (355-358) introducen el asunto que va a tratar el dios, a saber, el sitio galo en Roma. Como su intención es brindar ayuda a los romanos para que puedan sortear esa situación, apela a la responsabilidad de sus pares. Así es como el irónico scilicet inicial seguido de ignotum est evidencia el desentendimiento de los dioses respecto de la desafortunada (355), sufriente (356) y humillante (357) realidad romana. Al decir que 'evidentemente' las divinidades no estaban al tanto de los hechos, Marte relativiza la intencionalidad de la ausencia de respaldo divino y predispone a su auditorio para escuchar en qué consiste esto que ellos no saben (si tamen...exigis, 357-358) pues da por hecho que, de haber conocido las circunstancias, los demás dioses hubiesen obrado en consecuencia. Una vez finalizado el preámbulo, el relato pasa bruscamente a la descripción del presente de Roma (358) apelando, nuevamente, a elementos de orden espacial: tanto los quirites como sus enemigos son designados a partir de los territorios que los identifican (Alpino Roma 358). A su vez, una sintaxis hiperbática (Alpino Roma sub hoste iacet) exhibe el sometimiento de los romanos y parece graficar en el verso la perturbación de una ciudad sometida: lejos de adquirir una posición dominante, Roma está postrada (iacet) ante la fuerza de su enemigo; la ubicación del adjetivo Alpino delante de Roma y la posición del sustantivo hoste antes de iacet explicita en la fraseología la preeminencia del invasor; la preposición sub ubicada en el centro del sintagma, detrás de Roma y delante de hoste, insiste en la posición inferior de la 'ciudad eterna' respecto de los galos, quienes se constituyen aquí como agentes de poder. Más aún, el estado de sumisión de Roma en boca de Marte evoca el discurso de Eneas (A. 2.3-13) que introduce la historia de la caída de Troya, de modo tal que Fasti ubica a ambas ciudades en una situación especular a partir del motivo de la ruina de las dos ${ }^{35}$. Roma no parece responder, entonces, a los parámetros de la grandeza épica, sino que, por el contrario, se presenta maniatada y digna de compasión, imagen que el discurso de Marte exhibe en su pentámetro inicial a partir del léxico de la queja (dolor, querentis, 356), que resemantiza las palabras del héroe épico al volcarlas en el verso distintivamente elegíaco. Por otra parte, las sucesivas preguntas retóricas (359-360) insisten en el desafortunado presente del pueblo al que apadrina el dios y subrayan con la repetición pronominal anafórica (haec, hanc) el contraste con aquel imperium sine fine que el Tonante le había prometido otrora en el texto virgiliano ( $A$. 1.279). En este sentido, la potentia rerum (359) es promissa pero no se hace efectiva al momento del presente de la enunciación, al igual que ocurre con su poderío (terris impositurus, 360)

35 Cf. Merli (2000:162).

Argos 40 (2017) ISSN 0325-4194, pp. 84-104 
que no se concreta en el presente. La variación en los tiempos del verbo sum insiste en el incumplimiento de la promesa de Júpiter y remarca el contraste entre lo que este había asegurado (fuerat, 359; eras, 360) y la situación actual de Roma (est, 359).

A partir de estos cuestionamientos, el texto construye la ya mencionada indignatio de Marte y al mismo tiempo comienza a retratar a la Urbs como una víctima del asedio galo, como si el discurso del dios intentase despertar la commiseratio de sus interlocutores. Al reclamar la fortuna negada a Roma en términos que evocan, nuevamente, el discurso donde Venus pide a Júpiter un mejor destino para su hijo y la patria troyana ${ }^{36}$ (Verg. A. 1.229-253), el episodio ovidiano retoma el código épico, pero, al asemejar los dichos de Gradivo a los de una voz femenina que representa el dominio amoroso y plasmarlas en versos impares, se inclina hacia el ámbito temático de la elegía, lo cual resulta llamativo pues, en distintas situaciones a lo largo de los Fasti, la deidad de la guerra se muestra propensa al amor ${ }^{37}$. A su vez, el discurso de Marte demuestra lo enunciado y deja en claro la vigencia del lamento ante la imposibilidad de la consolidación heroica a través de un contexto de marcadas oposiciones: los versos 361-362 expanden el contraste previo entre la situación anterior de la ciudad y la presente, con vistas a subrayar el declive del poderío digno de un pueblo triunfador: el hexámetro destaca las conquistas romanas sobre otros espacios $^{38}$ (iamque suburbanos Etruscaque contudit arma, 361) e incluso extiende su contenido triunfalista al primer hemíepes del pentámetro (spes erat in cursu, 362), contenido que el corte central de este último verso interrumpe de manera tajante para retornar al presente de enunciación (nunc lare pulsa suo est, 362). La oposición que introduce el adverbio nunc (362) es duplicada no solo por el cambio en los tiempos verbales (erat - est), sino también por el contraste entre la sintaxis lineal del primer hemistiquio y la doble disociación sintáctica del segundo.

La historia del sitio que presenta Marte luego (363-366) retoma la antítesis con un pasado inmediato donde, a partir de dos escenas presentes en el relato de Livio, la circulación de los quirites en el espacio romano muestra una ciudad en declive (como demuestra la actitud de las Ves-

36 Esta coincidencia puede identificarse no solo en el contenido de ambos discursos sino, además, en la estructura de los mismos. Para estos detalles, cf. LiTTLEWOod (2006:115)

37 Cf. 3.1-70; 3.675-696.

38 Sobre la imagen de Roma como sociedad conquistadora, expansionista y dominadora de otros espacios, cf. Fast. 1.85-88: Iuppiter arce sua totum cum spectet in orbem, / nil nisi Romanum quod tueatur habet. / salve, laeta dies, meliorque revertere semper, / a populo rerum digna potente coli", [Cuando Júpiter contempla el mundo entero desde su fortaleza, no tiene nada que mirar que no sea romano. ¡Salud, día jubiloso, regresa siempre mejor, digno de ser honrado por el pueblo que ejerce su poder sobre el mundo!]. 
tales ${ }^{39}$, que al llevar los objetos sagrados a un lugar más seguro parecen proponer un cambio de la sedes divina: Iliacae transferri...pignora Vestae / sede, 365-366) pero que aún se erige dignamente (tal como deja ver el gesto de los ancianos senadores ${ }^{40}$ : picta / veste triumphales occubuisse senes, 363-364). La salvación parece estar en la huida (transferri, 365), mientras que quedarse en Roma implica conclusiones funestas (occubuisse, 364). La anáfora del verbo vidimus $(363 ; 365)$ resulta importante por dos motivos: en principio porque, como bien nota $\mathrm{Merli}^{41}$, remite a la mirada de Eneas sobre la ruina de Troya (vidi...vidi... A. 2.499-502) con lo cual vuelve a vincular la desgracia romana con la troyana; en segundo término porque la utilización de la primera persona del plural en el episodio ovidiano pone el presente de Roma ante los ojos de los dioses presentes en el concilium deorum a partir de una evidentia retórica: la repetición de los verbos al inicio de los hexámetros coincide con la distribución léxica de los pentámetros, que se inician con los términos que designan todo aquello perdido por los romanos (spes, 362; veste, 364; sede, 366), elementos que al corresponderse espacialmente en cada verso con la posición del Tonante (Iuppiter 360), parecen destacar cierta responsabilidad de este último en las actuales circunstancias de Roma. El padre de Rómulo remata dicho cuadro con un nuevo uso irónico de scilicet (366) que le permite reivindicar el cumplimiento de la pietas por parte de los romanos y comprometer a sus interlocutores a ayudarlos. El discurso instaura entonces un contraste con el abandono divino de los versos 367-370, encabezados por el adversativo at, que explicita el reproche a los interlocutores de Marte y pone en evidencia la infracción de ellos al desoír la atención que los romanos les brindan. En este último dístico (369-370) el dios amplía los ya citados versos que introducen el episodio que nos ocupa (6.351-352) y, mediante un mismo léxico, describe una Roma totalmente sitiada y acosada por el enemigo (obsidione premi, 368; premit, 374).

Marte expone finalmente una posible solución (371-372) en la que añora un espacio en el que sus romanos puedan luchar (utinam pugnae pateant locus, 370) empuñando las armas y, o bien ganar (exsuperare, 371), o bien perecer según el motivo épico de la muerte heroica (cadant, 372). $\mathrm{El}$ hecho de que el dios exprese su deseo mediante el verbo patere ${ }^{42} \mathrm{im}$ plica que, al momento de la enunciación, el espacio épico por excelencia se encuentra 'cerrado', y lo mismo parece ocurrir con la Roma asediada, cuestión que acentúa la imposibilidad de salir de allí. El último dístico del

39 Cf. Liv. 5.40.

40 Cf. Liv. 5.41.7.

41 Merli (2000:165).

42 Significa tanto 'estar disponible' y 'ser visible' como 'abrir', 'estar abierto', 'ser de libre acceso', OLD s.v. pateo.

Argos 40 (2017) ISSN 0325-4194, pp. 84-104 
parlamento (373-374) vuelve sobre el presente de la enunciación (nunc, 373) y, a diferencia de ese locus pugnae tan ansiado por el dios, presenta un sitio cuyos habitantes están absorbidos por el hambre (inopes victus, 373) y sienten temor (timentes, 373) ante una muerte cobarde (ignava fata, 373), lo cual confirma también un encierro en el Capitolio que los torna presos de sus propios 'cuarteles' (monte suo clausos, 374) en manos de una turba iracunda cuyas acciones son designadas, una vez más, con el verbo premere (374).

El espacio de batalla al que Marte apela parece ser, entonces, la misma Roma, que está a punto de configurarse como una ciudad perdedora que solo puede ofrecer hambre, muerte y deshonor: quienes allí se quedan, mueren; la única escapatoria es la huída que, además de ignominiosa, cada vez parece menos factible. La ciudad está a los pies de un pueblo bárbaro y el espacio sagrado del Capitolio, en peligro de ser profanado, constituye una trampa mortal que encierra a sus ciudadanos en la cima de la colina y les impide salir. Los elementos del presente son devastadores ya que, a diferencia de un pasado en el que Roma era un sitio vencedor y conquistador de nuevos espacios, cada nunc denota un sitio funesto y remarca la ausencia de este locus pugnae necesario para la reafirmación de la identidad romana como pueblo guerrero y triunfador. Dicho escenario cuestiona sin duda la configuración del espacio épico, que nunca llega a constituirse como tal (o, al menos, no para el lector romano), reduciéndose a una expresión de deseo y dando el lugar a espacios 'vencidos'. Al apelar a los rasgos propios de la heroicidad, el discurso de Marte habilita una interpretación del pasaje en términos metaliterarios: por un lado, los múltiples vínculos intertextuales que lo componen apelan a la convivencia de textos de diferente índole; por otro, el dios deposita su spes en la épica, lo cual le permitirá dejar de lado la indignatio y la commiseratio que él mismo construye mediante la alteración de ciertos motivos propios de la epopeya como, por ejemplo, la victoria en el campo de batalla o, en su defecto, una muerte excelsa y honorífica. Según veremos, la reacción de Júpiter profundiza en el texto esas alteraciones.

\section{La etiología de un nuevo espacio literario}

Tras el parlamento de Gradivo en la asamblea, tanto Venus como Quirino y Vesta (375-376) se posicionan pro Latio (376), según sabemos a través de los breves dichos del narrador; luego el mismo Tonante afirma que la preocupación por Roma es compartida (publica (...) cura est pro moenibus istis, 377) y, en señal de atención a los reclamos de Marte, parece anunciar una venganza épica sobre los galos (poenas Gallia victa dabit, 378). Júpiter toma a Vesta como interlocutora y determina lo siguiente: 
'tu modo, quae desunt fruges, superesse putentur

effice, nec sedes desere, Vesta, tuas.

380

quodcumque est solidae Cereris, cava machina frangat,

mollitamque manu duret in igne focus.' $\quad$ (Fast. 6.379-382)

Tú solo procura, Vesta, que crean que sobran los granos que faltan, y no abandones tu propia morada. Que la máquina hueca muela todo el trigo que está entero y que, amasado con la mano, el hogar lo endurezca en el fuego.

La estrategia del dios retoma el proceso de fabricación del pan por intermedio de Vesta (Vesta, 380; igne focus, 382), encargada de simular la abundancia de materia prima, cuestión que el hexámetro 379 destaca mediante la focalización del sustantivo fruges en el centro de un juego semántico (desunt / superesse) que reproduce el disimulo de la situación. El pedido de Júpiter a Vesta incluye que la diosa no abandone su sedes, imagen que evoca los versos 365-366 para apelar a la permanencia de esta deidad en la ciudad. El motivo de la producción panificadora a través de la máquina moledora (machina frangat, 381) y del trabajo manual (mollitam manu, 382) le permiten al dios traer a colación una actividad que alude tanto a la intervención del asinus como del proceso artesanal que llevaban a cabo las Vestales, lo cual recuerda nuevamente al animal que conserva la virginidad de la diosa y a las sacerdotisas encargadas de custodiar su llama, elemento fundamental no solo para la pervivencia de la ciudad sino para la fabricación del pan (como lo demuestra la yuxtaposición de los términos igne y focus), que funciona así como elemento mediador que garantiza doblemente la salvaguarda de Vesta y de Roma.

El relato ovidiano introduce el motivo épico del sueño al tomarlo como vehículo para las instrucciones nocturnas de Júpiter:

\section{'surgite, et in medios de summis arcibus hostes}

mittite, quam minime mittere voltis, opem.' (Fast. 6.387-388)

Levantaos y, desde la cima de la fortaleza, arrojad en medio del enemigo el recurso que menos queréis conceder.

La orden del dios subraya la disposición espacial de las acciones a realizar, dado que es en lo alto de la fortaleza (de summis arcibus, 387) donde los romanos 'encerrados' deberán ubicarse para actuar contra los enemigos, de modo que se apropiarán del espacio a partir de un movimien- 
to que va desde lo alto del Capitolio hacia la base de la ciudad ${ }^{43}$, donde espera el contingente enemigo que habrá de ser herido justo en el centro (in medios...hostes, 387). La distribución de las órdenes en los extremos iniciales de ambos versos (surgite, 387; mittite, 388) y del blanco de la primera directiva y el objeto de la segunda al final de los mismos (hostes, 387; opem, 388) sugieren, a partir de la simetría verbal, que ambas acciones serán ejecutadas exitosamente. No obstante, la pretensión épica de Marte no parece concretarse del todo puesto que la 'herida de guerra' no será efectuada por medio del hierro sino del pan:

somnus abit, quaeruntque, novis ambagibus acti,

tradere quam nolint et iubeantur opem.

390

esse Ceres visa est; iaciunt Cerialia dona:

iacta super galeas scutaque longa sonant.

posse fame vinci spes excidit: hoste repulso

candida Pistori ponitur ara Iovi. (Fast. 6.389-394)

El sueño se marcha y [ellos], movilizados por un nuevo enigma, se preguntan qué recurso no querrían y se les ordena entregar. Les pareció que era Ceres; arrojan los dones de Ceres. Una vez caídos, resuenan sobre los cascos y los largos escudos. Se perdió la esperanza de poder ser vencidos por el hambre: rechazado el enemigo, se levanta un altar blanco para Júpiter Pistor.

La insistencia en la intervención del pan se resalta en el hexámetro 391 (Ceres...Cerialia) y, según señalan Newlands ${ }^{44}$ y Merli $^{45}$, parece darle a la escena un matiz de comicidad dada la tergiversación de las batallas épicas convencionales, efecto que, como nota la última autora, se destaca aún más con la ubicación de términos marciales en el pentámetro (galeas scutaque, 392). De hecho, el sonido del pan contra las armas de los galos parece emular el de las armas de guerra ${ }^{46}$. En un mismo sentido, el verso 393 aúna todos los elementos mencionados en la descripción de la Roma asediada (fames, vinci, spes) y presenta la solución por medio de la expulsión de los galos (hoste repulso), lo cual da origen a la etiología del templo de Júpiter Pistor (394). Parece evidente entonces que el resulta-

43 De modo similar repelen los romanos a los galos en Liv. 5.43.2, donde se cuenta que el ejército local permitía que sus enemigos escalasen el Capitolio pues, cuando más alto llegaban, más sencillo era empujarlos hacia abajo.

44 Cf. Newlands (1995:135).

45 Cf. Merli (2000:179-180).

46 Esto comprueba la llegada de Marte a Roma en Fast. 5.549: fallor, an arma sonant? non fallimur, arma sonabant [¿ंMe engaño, o hay ruido de armas? No me engaño, había ruido de armas]. 
do de este enfrentamiento poco y nada se corresponde con la tradicional victoria sobre el enemigo: el locus pugnae presuntamente recuperado no es otro que un 'locus pani'. Tras lograr el objetivo y tal como solía hacerse con las divinidades que ofrecían sus favores en las batallas, se levanta un altar para Júpiter y se le asigna el epíteto Pistor. Dicho epíteto funciona no solo como recuerdo de la treta preparada junto a Vesta, sino que le permite al ego poético vincular narrativamente esta etiología con la fiesta de los panaderos que se celebraba durante los Vestalia, incluyendo así un nuevo elemento en el espacio romano, vinculado con las celebraciones de esta comunidad y rememorativo de la salvaguarda de la ciudad por intermedio del pan.

\section{Conclusiones}

Según hemos constatado, la configuración del espacio constituye una interesante vía de acceso al episodio de Fasti que presenta la etiología del templo de Júpiter Pistor en el libro 6. En efecto, dado que la construcción de un templo implica una modificación del espacio en el que se inscribe y responde a una serie de motivos socio-culturales, entendemos que dicha etiología presenta, a partir de este nuevo sitio cultual, la conmemoración de la salvación de Roma no por las armas sino por el pan, cuestión que también recuerda las dificultades de los romanos para hacerse de su propio espacio de batalla durante el asedio galo. Las particularidades de la versión ovidiana de este episodio insisten en la ausencia del ansiado locus pugnae a partir de la tergiversación de distintos motivos propios del género épico. Estos se acercan al ámbito de la elegía en el marco de un entrecruzamiento de ambos códigos, según deja al descubierto el pasaje estudiado y, de un modo más general, los mismos Fasti al desarrollar asuntos de tenor épico en un soporte elegíaco. 


\section{Bibliografia}

Alton, E.H.; Wormell, D.E.W. E Courtney, E. (eds.) (1985) P. Ovidii Nasonis Fastorum Libri Sex, Leipzig.

Barchiesi, A. (1994 [1997]) The Poet and the Prince. Ovid and Augustan Discourse, Berkeley, Los Angeles, London.

Bömer, F. (ed.) (1957-1958) P. Ovidius Naso. Die Fasten, 2 vols., Heidelberg.

Canal, L. (1998) Ovidio. I Fasti. Introduzione e traduzione. Note di M. Fucecchi, Milano.

Dalzell, A. (1996) The Criticism of Didactic Poetry. Essays on Lucretius, Vergil and Ovid, Toronto.

De Certeau, M. (2007) La invención de lo cotidiano I. Artes de hacer, México.

FANTHAM, E. (1983) "Sexual Comedy in Ovid's Fasti: Sources and Motivations", HCPh 87, 185-216.

Frazer, J.G. (1929) Publii Ovidii Nasonis Fastorum Libri Sex, London.

Glare, P. (ed.) (1997) Oxford Latin Dictionary, Oxford.

HARRIES, B. (1991) "Ovid and the Fabii: Fasti 2.193-474", CQ 41, 1, 150-168. Heinze (1919) Ovids Elegische Erzahlung, Leipzig.

Horsfall, N. (1981) "From History to Legend: M. Manlius and the Geese", CJ 76, 4, 298311.

LitTlewood, R.J. (2006) A commentary on Ovid's Fasti Book 6, Oxford.

MaleuvRE, J-Y. (1997) "Les Fastes d'Ovide ou la guerre du calendrier", RBA 75, 1, 9-105.

MerLi, E. (2000) Arma canant alii. Materia epica e narrazione elegiaca nei Fasti di Ovidio, Firenze.

Newlands, C. (1995) Playing with time. Ovid and the Fasti, Ithaca.

Newlands, C. (2005) "Ovid", en Foley, J. M. (ed.), A companion to Ancient Epic, Blackwell, 476-491.

Ogilvie, R.M. (1965) A Commentary on Livy. Books 1-5, Oxford.

OrLin, E. (1997) Temples, Religion and Politics in the Roman Republic, Leyden.

Pasco-Pranger, M. (2006) Founding the year: Ovid's Fasti and the poetics of the Roman calendar, Leyden.

PICHON, R. (1991) Index verborum amatorium, Hildesheim.

Richard, J-C. (1990) "Les Fabii à la Crémère: grandeur et décadence de l'organisation gentilice", Crise et transformation des sociétés archaïques de l'Italie antique au Ve siècle au. JC. Actes de la table ronde de Rome (19-21 novembre), Rome, École Française de Rome, 245-262. Robinson, M. (2011) A Commentary on Ovid's Fasti Book 2, Oxford. Schilling, R. (1993) Ovide. Les Fastes. Tomes I-II. Paris, Les Belles Lettres. 
Schniebs, A. (2016) "Lugares, poder y representación en las Metamorfosis de Ovidio", en Campagno, M. - Gallego, J. - García Mac Gaw (comps.), Regímenes políticos en el Mediterráneo Antiguo, Buenos Aires, 225238.

SKEMPIS - Zlogas (2014) "Introduction: Putting Epic Space in Context", en SKEMPIS - ZIOGAS (eds.), Geography, Topography, Landscape. Configurations of Space in Greek and Roman Epic, Berlin - Boston, 1-16.

Stambaugh, J.E. (1978) "The Functions of Roman Temples", ANRW 2, 16, 1, 554-608.

WiLliams, G. (1991) "Vocal Variations and Narrative Complexity in Ovid's Vestalia: 'Fasti' 6. 249-468”, Ramus 20, 2, 183-204.

Fecha de recepción: 30-07-2017

Fecha de aceptación: 21-03-2018 